\title{
One-year outcomes in 1,010 unselected patients treated with the PROMUS Element everolimus-eluting stent: the multicentre PROMUS Element European Post-Approval Surveillance Study
}

\author{
Martyn R. Thomas ${ }^{1 *}, \mathrm{MD}, \mathrm{PhD}$; Ralf Birkemeyer ${ }^{2}$, MD; Peter Schwimmbeck ${ }^{3}, \mathrm{MD}, \mathrm{PhD}$; \\ Victor Legrand ${ }^{4}$, MD, PhD; Raul Moreno ${ }^{5}$, MD; Carlo Briguori ${ }^{6}$, MD; Nikos Werner7, MD; \\ Ezio Bramucci ${ }^{8}, \mathrm{MD}$; Imre Ungi ${ }^{9}$, MD; Gert Richardt ${ }^{10}, \mathrm{MD}, \mathrm{PhD}$; Paul L. Underwood ${ }^{11}$, MD; \\ Keith D. Dawkins ${ }^{11}$, MD
}

1. Guy's and St. Thomas' National Health Service Foundation Trust, London, United Kingdom; 2. Universitätsklinikum Rostock, Rostock, Germany; 3. Klinikum Leverkusen, Leverkusen, Germany; 4. Centre Hospitalier Universitaire Sart Tilman, Liege, Belgium; 5. Hospital La Paz, Madrid, Spain; 6. Clinica Mediterranea, Naples, Italy; 7. Universitätsklinikum Bonn, Bonn, Germany; 8. IRCCS Policlinico S. Matteo, Pavia, Italy; 9. University of Szeged, Szeged, Hungary; 10. Herzzentrum, Segeberger Kliniken GmbH, Bad Segeberg, Germany; 11. Boston Scientific Corporation, Marlborough, MA, USA

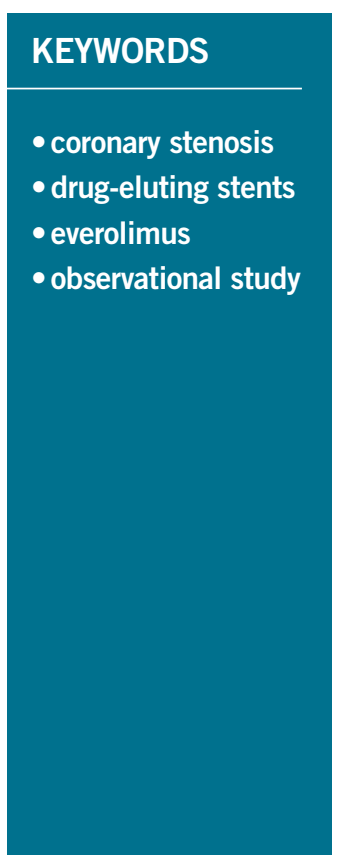

\begin{abstract}
Aims: The PROMUS ${ }^{\mathrm{TM}}$ Element ${ }^{\mathrm{TM}}$ European Post-Approval Surveillance Study (PE-Prove) is a prospective, open-label, multicentre observational study designed to assess outcomes following PROMUS Element everolimus-eluting stent implantation in an unselected patient population.
\end{abstract}

Methods and results: A total of 1,010 patients were enrolled at 40 clinical sites in Europe, including $24.9 \%$ with medically treated diabetes, $50.0 \%$ with Type B2/C lesions, $6.1 \%$ with chronic total occlusion, $17.8 \%$ with acute myocardial infarction ( $\mathrm{MI} \leq 24$ hours pre-procedure), and $20.1 \%$ with unstable angina. The target lesion was the culprit for ST-segment elevation MI in 7.3\% of patients. The one-year, per patient target vessel failure rate was 6.2\% (60/975), 3.4\% (33) being related to the PROMUS Element stent. Rates of cardiac death, MI, and Academic Research Consortium (ARC) definite/probable stent thrombosis were 1.7\%, 3.5\%, and $0.6 \%$, respectively. The target vessel revascularisation rate was 3.2\% (31/975), 2.1\% (20) being related to the PROMUS Element stent.

Conclusions: In a large and relatively complex group of "real-world" patients, coronary artery revascularisation with the PROMUS Element everolimus-eluting stent provides favourable results with low event rates consistent with those reported for other contemporary drug-eluting stents.

\footnotetext{
*Corresponding author: Guy's and St Thomas'NHS Foundation Trust, St Thomas'Hospital, East Wing, 6th Floor, Lambeth Palace Road, London, SE1 7EH, United Kingdom.E-mail: mttwins@aol.com
} 


\section{Introduction}

As new coronary stent designs become approved and more widely available for use in large, unselected populations outside of controlled clinical trials, it is important to evaluate their safety and effectiveness in broader "real-world" application. The PROMUS Element ${ }^{\mathrm{TM}}$ coronary stent (Boston Scientific Corporation, Marlborough, MA, USA) is a thin-strut, platinum chromium alloy stent coated with a durable, biocompatible, inert fluorocopolymer and everolimus as the antiproliferative agent. In the randomised controlled PLATINUM trial, the PROMUS Element stent was shown to be non-inferior to the predicate XIENCE V/PROMUS stent (Boston Scientific) for the primary endpoint of one-year target lesion failure'. Rates of all-cause death, cardiac death, myocardial infarction, stent thrombosis, and revascularisation were comparable between the two treatment groups at three-year follow-up ${ }^{2}$.

The PROMUSTM Element ${ }^{\mathrm{TM}}$ European Post-Approval Surveillance Study (PE-Prove) is an observational study designed to collect data on long-term outcomes in a large and relatively complex group of "real-world" patients treated with the PROMUS stent. We report here the one-year primary endpoint clinical outcomes, evaluating the safety and efficacy of this stent in a large, unselected patient population.

\section{Methods}

This prospective, open-label, multicentre study with an all-comers approach was designed to enrol approximately 1,000 patients at 40 sites in Europe.

\section{PATIENT SELECTION, PROCEDURE, AND FOLLOW-UP}

All patients who were candidates for coronary artery stenting and eligible to receive a PROMUS Element stent were evaluated for enrolment in this study. All enrolled patients signed a written informed consent form that had been approved by the independent ethics committee at each study site. Enrolment was considered complete upon signing the informed consent form. This study was conducted in accordance with the ethical principles originating in the Declaration of Helsinki and consistent with good clinical practice and applicable local regulatory requirements (ClinicalTrials.gov NCT01148329).

Follow-up assessments, including medications, NYHA/CCS classification, adverse events, and coronary angiograms performed according to standard of care at each study site, were carried out by clinic visit or phone call at 30 days, six months, and 12 months post index stent implantation, and will continue annually to five years.

\section{STUDY ENDPOINTS}

The primary endpoint of this study was the overall and PROMUS Element stent-related target vessel failure (TVF) rate, defined as cardiac death, myocardial infarction (MI) related to the target vessel, or target vessel reintervention (TVR), at 12 months post stent implantation. Secondary endpoints are detailed in the Online Appendix. An independent clinical events committee adjudicated all deaths, MI, TVR, and stent thrombosis, including the relationship of the event to the study stent.

\section{STATISTICAL METHODS}

Enrolled patients who received at least one PROMUS Element stent in the target lesion were included in the analysis. Statistical analyses were performed using $\mathrm{SAS}^{\circledR}$, Version 9 or later (SAS Institute Inc., Cary, NC, USA). Further details are provided in the Online Appendix.

\section{Results}

\section{PATIENT, LESION, AND PROCEDURAL CHARACTERISTICS}

Of 1,010 patients enrolled at 40 clinical sites in Europe between 28 June 2010 and 20 April 2011, one-year clinical follow-up was available for 975 (96.5\%) patients (Figure 1). Baseline patient and lesion characteristics are shown in Table 1.

Procedural characteristics are shown in Online Table 1. Successful deployment of the PROMUS Element stent to the target lesion without device malfunction (i.e., technical success) was achieved in $99.8 \%(1,008 / 1,010)$ of patients. Two cases of longitudinal stent deformation were detected by angiography during the index procedure, both of which involved $<5 \%$ proximal stent compression. Details of these cases are provided in the Online Appendix.

\section{ONE-YEAR CLINICAL OUTCOMES}

As shown in Table 2, the overall one-year TVF rate was $6.2 \%$ and TVF related to the PROMUS Element stent was 3.4\%. The rates of cardiac death, MI, and TVR related to the PROMUS Element stent were $0.4 \%, 2.1 \%$, and $2.1 \%$, respectively. ARC-defined definite/ probable stent thrombosis related to the PROMUS Element stent was reported in six patients $(0.6 \%)$. In Figure 2, showing KaplanMeier time-to-event analyses for overall TVF and definite/probable stent thrombosis at one-year follow-up, there were no stent thromboses reported beyond eight months post procedure. One-year clinical outcomes for selected high-risk patient subgroups are also shown in Table 2. Relative to the study population as a whole, rates of overall and PROMUS Element-related TVF and ARC-defined definite/probable stent thrombosis were only modestly higher in patients with medically treated diabetes or long lesions $(>28 \mathrm{~mm}$

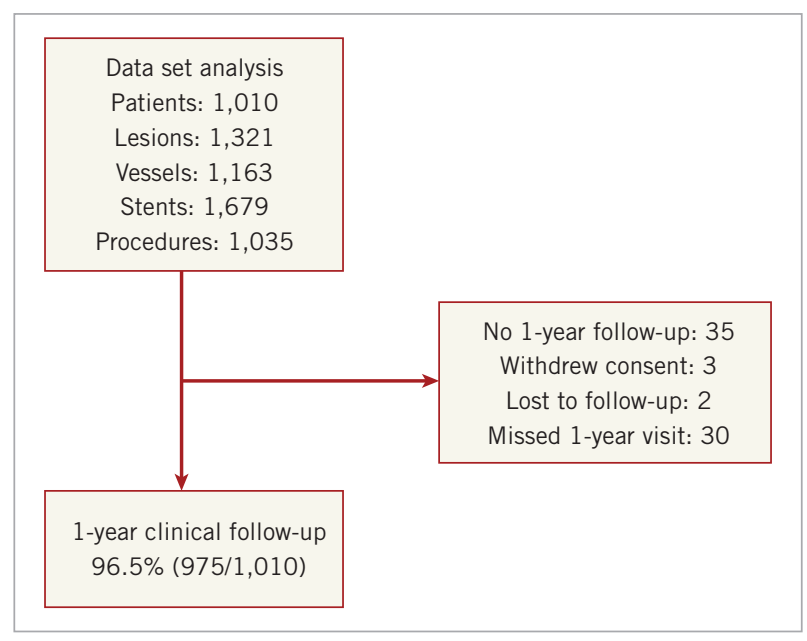

Figure 1. PE-Prove registry enrolment and follow-up. 
Table 1. Baseline patient and lesion characteristics.

Patient characteristics (per patient)

\begin{tabular}{|c|c|c|}
\hline \multicolumn{2}{|l|}{ Age (years) } & $64.7 \pm 11.2$ \\
\hline \multicolumn{2}{|l|}{ Male } & $75.4 \%(762 / 1,010)$ \\
\hline \multicolumn{2}{|l|}{ Hypertension* } & $70.2 \%(709 / 1,010)$ \\
\hline \multicolumn{2}{|c|}{ Hyperlipidaemia* } & $68.2 \%(689 / 1,010)$ \\
\hline \multicolumn{2}{|l|}{ Diabetes* } & $24.9 \%(251 / 1,010)$ \\
\hline \multicolumn{2}{|c|}{ Insulin-treated diabetes } & $8.2 \%(83 / 1,010)$ \\
\hline \multicolumn{2}{|l|}{ Current smoker } & $24.6 \%(248 / 1,010)$ \\
\hline \multicolumn{2}{|l|}{ Prior $\mathrm{PCl}$} & $38.8 \%(392 / 1,010)$ \\
\hline \multicolumn{2}{|l|}{ Prior CABG } & $8.0 \%(81 / 1,010)$ \\
\hline \multicolumn{2}{|c|}{ History of congestive heart failure } & $11.6 \%(117 / 1,010)$ \\
\hline \multicolumn{2}{|c|}{ History of multivessel disease } & $35.8 \%(362 / 1,010)$ \\
\hline \multicolumn{2}{|c|}{ History of bleeding disorder } & $1.3 \%(13 / 1,010)$ \\
\hline \multicolumn{2}{|c|}{ History of renal disease } & $9.9 \%(100 / 1,010)$ \\
\hline \multicolumn{2}{|c|}{ Prior MI (>24 hrs before index procedure) } & $34.4 \%(347 / 1,010)$ \\
\hline \multicolumn{2}{|c|}{ Prior MI ( $\leq 24 \mathrm{hrs}$ before index procedure) } & $17.8 \%(180 / 1,010)$ \\
\hline \multirow{6}{*}{$\begin{array}{l}\text { Current } \\
\text { angina status }\end{array}$} & Stable angina & $40.8 \%(412 / 1,010)$ \\
\hline & Silent ischaemia & $10.8 \%(109 / 1,010)$ \\
\hline & ACS/unstable angina & $13.9 \%(140 / 1,010)$ \\
\hline & ACS/STEMI & $8.0 \%(81 / 1,010)$ \\
\hline & ACS/NSTEMI & $9.8 \%(99 / 1,010)$ \\
\hline & Unknown & $24.1 \%(243 / 1,010)$ \\
\hline
\end{tabular}

Target lesion characteristics (per lesion) 1,321 lesions \% (n/N)

Culprit lesion for STEMI

De novo lesions

In-stent restenosis (DES)

In-stent restenosis (BMS)

Total occlusion ( $<3$ months)

Chronic total occlusion ( $>3$ months)

Left main stenting

Bifurcation lesion

AHA/ACC type B2/C

Pre-procedure TIMI flow 0/1

Moderate/severe calcification

Moderate/severe tortuosity

Thrombus present

Reference vessel diameter, $\mathrm{mm}$

Lesion length, $\mathrm{mm}$

Diameter stenosis, \%

Intent-to-treat analysis set. Values are mean $\pm \mathrm{SD}(\mathrm{N})$ or $\%(\mathrm{n} / \mathrm{N})$.

Denominators may differ due to missing data. *Requiring medication.

IPatients may be reported in more than one angina category (for

example, a patient with silent ischaemia who subsequently had elevated

enzymes could be reported in both categories). BMS: bare metal stent;

CABG: coronary artery bypass graft; DES: drug-eluting stent; MI:

myocardial infarction; $\mathrm{PCI}$ : percutaneous coronary intervention; STEMI:

ST-segment elevation MI

single lesion), whereas rates among patients with small vessels $(\leq 2.5 \mathrm{~mm})$ were similar to the overall study population rates.

At the time of the one-year follow-up visit, 79.6\% (756/950) of patients were taking dual antiplatelet therapy, including $96.8 \%$ (920/950) on aspirin, 76.1\% (723/950) on clopidogrel, $6.2 \%$ (59/950) on prasugrel, and $0.1 \%$ (1/950) on ticagrelor.

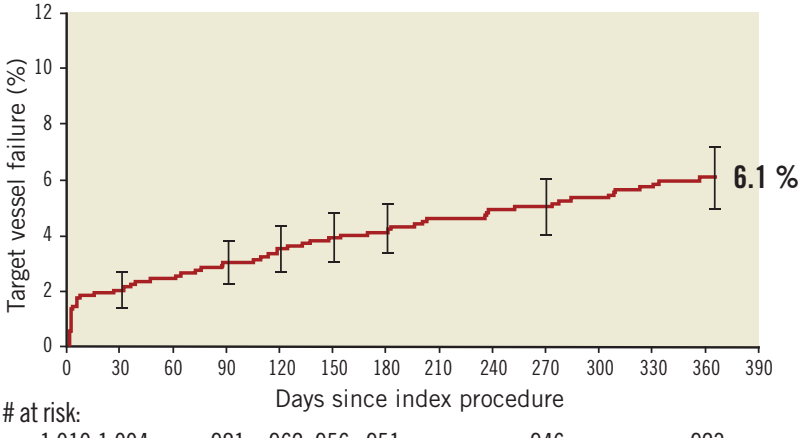

$\begin{array}{llllll}1,0101,004 & 981 & 962956951 & 946 & 923\end{array}$

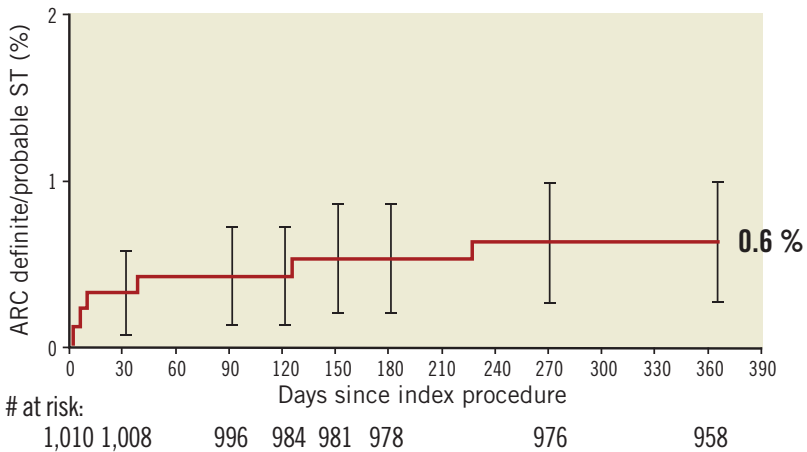

Figure 2. Kaplan-Meier time-to-event analyses baseline to one year. A) Target vessel failure. B) ARC-defined definite/probable stent thrombosis.

\section{PREDICTORS OF TARGET VESSEL FAILURE AT ONE YEAR}

Multivariate predictors of TVF within one year of stent implantation are shown in Online Figure 1. Diabetes, post-procedure dilation, and prior PCI were identified as predictors of both overall TVF and PROMUS Element stent-related TVF. The strongest predictor of overall TVF was the use of thienopyridines for six months or less, and the strongest predictor of TVF associated with the PROMUS Element stent was implantation in a vein graft.

\section{Discussion}

In this large, "real-world" population, one-year rates of cardiac death, MI, TVR, and stent thrombosis related to the PROMUS Element stent were low and consistent with rates in the randomised controlled PLATINUM trial of this stent ${ }^{1}$. Overall, clinical event rates for patients with small calibre vessels $(\leq 2.5 \mathrm{~mm})$ were similar to the rates in the study population as a whole.

As might be expected, medically treated diabetes and single lesion length $>28 \mathrm{~mm}$ were each associated with modestly increased rates of cardiac events. The technical success rate of $99.8 \%$ reflects good deliverability of this stent, which is perhaps a reflection of the conformability and flexibility of this stent platform.

\section{DES IN ROUTINE PRACTICE}

This study contributes to a vast and growing body of "real-world" data on contemporary DES outcomes. Studies of DES that have used broad inclusion criteria or an all-comers approach include 
Table 2. One-year clinical outcomes in patients receiving the PROMUS Element stent.

\begin{tabular}{|c|c|c|c|c|}
\hline & $\begin{array}{l}\text { All patients } \\
(N=1,010)\end{array}$ & $\begin{array}{l}\text { Medically treated } \\
\text { diabetes }(N=251)\end{array}$ & $\begin{array}{c}\text { Long lesions* } \\
(>28 \mathrm{~mm})(\mathrm{N}=157)\end{array}$ & $\begin{array}{l}\text { Small diameter vessels } \\
(\mathrm{RVD} \leq 2.5 \mathrm{~mm})(\mathrm{N}=280)\end{array}$ \\
\hline Target vessel failure & $6.2 \%(60 / 975)$ & $11.0 \%(26 / 237)$ & $7.8 \%(12 / 154)$ & $6.6 \%(18 / 273)$ \\
\hline Related to PROMUS Element & $3.4 \%(33 / 975)$ & $6.3 \%(15 / 237)$ & $5.8 \%(9 / 154)$ & $4.0 \%(11 / 273)$ \\
\hline Major adverse cardiac events & $6.6 \%(64 / 975)$ & $12.2 \%(29 / 237)$ & $8.4 \%(13 / 154)$ & $7.7 \%(21 / 273)$ \\
\hline All death or MI & $5.4 \%(53 / 975)$ & $12.2 \%(29 / 237)$ & $7.8 \%(12 / 154)$ & $6.6 \%(18 / 273)$ \\
\hline Cardiac death or MI & $4.6 \%(45 / 975)$ & $11.0 \%(26 / 237)$ & $6.5 \%(10 / 154)$ & $5.9 \%(16 / 273)$ \\
\hline Related to PROMUS Element & $2.3 \%(22 / 975)$ & $5.5 \%(13 / 237)$ & $4.5 \%(7 / 154)$ & $2.9 \%(8 / 273)$ \\
\hline All death & $2.7 \%(26 / 975)$ & $5.9 \%(14 / 237)$ & $2.6 \%(4 / 154)$ & $2.6 \%(7 / 273)$ \\
\hline Non-cardiac death & $0.9 \%(9 / 975)$ & $1.7 \%(4 / 237)$ & $1.3 \%(2 / 154)$ & $1.1 \%(3 / 273)$ \\
\hline Cardiac death & $1.7 \%(17 / 975)$ & $4.2 \%(10 / 237)$ & $1.3 \%(2 / 154)$ & $1.5 \%(4 / 273)$ \\
\hline Related to PROMUS Element & $0.4 \%(4 / 975)$ & $1.7 \%(4 / 237)$ & $0.6 \%(1 / 154)$ & $0.4 \%(1 / 273)$ \\
\hline Related to target vessel & $0.6 \%(6 / 975)$ & $1.7 \%(4 / 237)$ & $0.6 \%(1 / 154)$ & $0.7 \%(2 / 273)$ \\
\hline $\mathrm{MI}$ & $3.5 \%(34 / 975)$ & $8.0 \%(19 / 237)$ & $5.2 \%(8 / 154)$ & $5.1 \%(14 / 273)$ \\
\hline Related to PROMUS Element & $2.1 \%(20 / 975)$ & $4.6 \%(11 / 237)$ & $3.9 \%(6 / 154)$ & $2.9 \%(8 / 273)$ \\
\hline Related to target vessel & $2.7 \%(26 / 975)$ & $5.9 \%(14 / 237)$ & $3.9 \%(6 / 154)$ & $3.3 \%(9 / 273)$ \\
\hline Q-wave MI & $0.3 \%(3 / 975)$ & $1.3 \%(3 / 237)$ & $0.0 \%(0 / 154)$ & $0.4 \%(1 / 273)$ \\
\hline Non-Q-wave MI & $3.2 \%(31 / 975)$ & $6.8 \%(16 / 237)$ & $5.2 \%(8 / 154)$ & $4.8 \%(13 / 273)$ \\
\hline Target vessel revascularisation & $3.2 \%(31 / 975)$ & $4.6 \%(11 / 237)$ & $4.5 \%(7 / 154)$ & $3.3 \%(9 / 273)$ \\
\hline Related to PROMUS Element & $2.1 \%(20 / 975)$ & $3.8 \%(9 / 237)$ & $3.9 \%(6 / 154)$ & $2.2 \%(6 / 273)$ \\
\hline ARC definite/probable stent thrombosis & $0.6 \%(6 / 975)$ & $2.1 \%(5 / 237)$ & $1.3 \%(2 / 154)$ & $0.7 \%(2 / 273)$ \\
\hline Related to PROMUS Element & $0.6 \%(6 / 975)$ & $2.1 \%(5 / 237)$ & $1.3 \%(2 / 154)$ & $0.7 \%(2 / 273)$ \\
\hline
\end{tabular}

the PEXIP study of the XIENCE Prime and PROMUS Element everolimus-eluting stents $^{3}$, the Swedish Coronary Angiography and Angioplasty Registry (SCAAR) analysis of the PROMUS Element stent relative to other contemporary DES ${ }^{4}$, the XIENCE V USA study of the XIENCE V stent ${ }^{5}$, the PROENCY registry of the PROMUS everolimus-eluting stent, CYPHER sirolimus-eluting stent, and ENDEAVOR zotarolimus-eluting stent ${ }^{6}$, the COMPARE study of the PROMUS everolimus-eluting stent and the TAXUS Liberte stent $^{7}$, and three studies of the Resolute zotarolimus-eluting stent, including the RESOLUTE International Registry ${ }^{8}$, the Resolute All Comers trial ${ }^{9}$, and the TWENTE trial ${ }^{10}$, the latter two both evaluating the Resolute stent versus the XIENCE V stent.

One-year clinical event rates with the PROMUS Element stent in this study are well within the one-year ranges reported from these other all-comers DES studies. The PROMUS Element all-cause mortality rate was $2.7 \%$ (other studies $1.6 \%$ to $2.8 \%$ ), the rate of MI related to the PROMUS Element was $2.1 \%$ (other studies $0.7 \%$ to $7.9 \%$ ), and the rate of TVR related to the PROMUS Element was $2.1 \%$ (other studies $1.3 \%$ to $8.2 \%)^{3-10}$. The $0.6 \%$ rate of ARC-defined definite/probable stent thrombosis is in the lower range among the all-comers DES studies (other studies $0.0 \%$ to $1.6 \%)^{3-6,8-11}$.

\section{STENT DEFORMATION}

The occurrence of two cases of longitudinal stent deformation (change in axial length) out of 1,679 stents placed in this study highlights the low frequency of this procedural complication. These two cases of stent deformation, which were detected by angiography during the index procedure, represent classic examples of stent deformation resulting from interaction between an ancillary device and a stent that were easily treated without severe adverse consequences.

\section{LIMITATIONS}

As a single-arm registry, this study has inherent limitations. Without a control group, the performance of the PROMUS Element stent cannot be directly compared with other contemporary DES. In addition, the broad inclusion criteria and observational design present challenges for evaluating outcomes across studies in which the "all-comers" design results in diverse patient and lesion characteristics. Finally, clinical follow-up at one year was not available for $3.5 \%$ of these unselected patients, mostly due to missed visits. Although this represents an acceptable rate of follow-up for a postmarket, all-comers registry, given the very low rate of events at one year with this contemporary stent, the potential effect of these missing data should be taken into account when considering the oneyear clinical event rates.

\section{CONCLUSIONS}

In this large and relatively complex group of "real-world" patients, coronary artery revascularisation with the PROMUS Element everolimus-eluting stent resulted in low clinical event rates consistent with those reported for other contemporary DES. 


\section{Impact on daily practice}

Although randomised controlled trials remain the gold standard for proving the safety and efficacy of new devices in clinical practice, the strict inclusion and exclusion criteria typically used in these trials mean that the results may not be generalisable to an unselected, "real-world" clinical population. This large, multicentre registry presents valuable information on outcomes from everyday clinical practice with the use of the PROMUS Element stent in more than 1,000 patients in Europe. The consistency of the results from this more complex clinical population with those of the randomised controlled trial provide reassurance to the treating physician of good clinical outcomes with the PROMUS Element stent, regardless of patient comorbidities and anatomic complexity.

\section{Acknowledgements}

The authors would like to thank all of the sites that enrolled patients in the PE-Prove study, as well as the clinical events committee members and the associated research organisations (Online Table 2, Online Table 3 ). In addition, the authors gratefully acknowledge Laurie LaRusso (Chestnut Medical Communications) and Kristin L. Hood (Boston Scientific Corporation) for assistance with manuscript preparation, Shannon Song (Boston Scientific) and Srikanth Garre (Quintiles) for statistical assistance, and Thomas Naeschen (Boston Scientific) for project management.

\section{Funding}

This study was sponsored and funded by Boston Scientific Corporation, Marlborough, MA, USA.

\section{Conflict of interest statement}

R. Moreno reports lecture and consulting fees from Boston Scientific, Abbott, Cordis, Medtronic, Terumo, and Biotronik. G. Richardt reports serving on an advisory board and receiving speakers' honoraria from Boston Scientific. M. Thomas reports serving on an advisory board for Boston Scientific. P. Underwood and K. Dawkins are full-time employees with equity interest in Boston Scientific. The other authors have no conflicts of interest to declare.

\section{References}

1. Stone GW, Teirstein PS, Meredith IT, Farah B, Dubois CL, Feldman RL, Dens J, Hagiwara N, Allocco DJ, Dawkins KD; PLATINUM Trial Investigators. A prospective, randomized evaluation of a novel everolimus-eluting coronary stent: the PLATINUM (a Prospective, Randomized, Multicenter Trial to Assess an EverolimusEluting Coronary Stent System [PROMUS Element] for the Treatment of Up to Two de Novo Coronary Artery Lesions) trial. J Am Coll Cardiol. 2011;57:1700-8.

2. Meredith IT, Teirstein PS, Bouchard A, Carrie D, Mollmann H, Oldroyd KG, Hall J, Allocco DJ, Dawkins KD, Stone GW. Three-year results comparing platinum-chromium PROMUS element and cobalt-chromium XIENCE V everolimus-eluting stents in de novo coronary artery narrowing (from the PLATINUM Trial). Am J Cardiol. 2014;113:1117-23.
3. De la Torre Hernandez JM, Garcia Camarero T, Lerena P, Lee DH, Sainz Laso F, Gorria GM, Zueco J. A real all-comers randomized trial comparing Xience Prime and Promus Element stents. $J$ Invasive Cardiol. 2013;25:182-5.

4. Sarno G, Lagerqvist B, Carlsson J, Olivecrona G, Nilsson J, Calais F, Gotberg M, Nilsson T, Sjogren I, James S. Initial clinical experience with an everolimus eluting platinum chromium stent (Promus Element) in unselected patients from the Swedish Coronary Angiography and Angioplasty Registry (SCAAR). Int J Cardiol. 2013;167:146-50.

5. Krucoff MW, Rutledge DR, Gruberg L, Jonnavithula L, Katopodis JN, Lombardi W, Mao VW, Sharma SK, Simonton CA, Tamboli HP, Wang J, Wilburn O, Zhao W, Sudhir K, Hermiller JB. A new era of prospective real-world safety evaluation: Primary report of XIENCE V USA (XIENCE V Everolimus Eluting Coronary Stent System condition-of-approval post-market study). JACC Cardiovasc Interv. 2011;4:1298-1309.

6. Damman P, Abdel-Wahab M, Mollmann H, Richardt G, Chevalier B, Barragan P, Tijssen JG, Underwood P, Hamm CW. Comparison of twelve-month outcomes after percutanous coronary intervention with everolimus-eluting versus zotarolimus-eluting or sirolimus-eluting stents from the PROENCY (PROmus ENdeavor CYpher) registry. J Invasive Cardiol. 2012;24:495-502.

7. Kedhi E, Joesoef KS, McFadden E, Wassing J, van Mieghem C, Goedhart D, Smits PC. Second-generation everolimus-eluting and paclitaxel-eluting stents in real-life practice (COMPARE): a randomised trial. Lancet. 2010;375:201-9.

8. Neumann FJ, Widimsky P, Belardi JA. One-year outcomes of patients with the zotarolimus-eluting coronary stent: RESOLUTE International Registry. EuroIntervention. 2012;7:1181-8.

9. Silber S, Windecker S, Vranckx P, Serruys PW. Unrestricted randomised use of two new generation drug-eluting coronary stents: 2-year patient-related versus stent-related outcomes from the RESOLUTE All Comers trial. Lancet. 2011;377:1241-7.

10. von Birgelen C, Basalus MW, Tandjung K, van Houwelingen KG, Stoel MG, Louwerenburg JH, Linssen GC, Said SA, Kleijne MA, Sen H, Lowik MM, van der Palen J, Verhorst PM, de Man FH. A randomized controlled trial in second-generation zotarolimus-eluting Resolute stents versus everolimus-eluting Xience V stents in realworld patients: the TWENTE trial. J Am Coll Cardiol. 2012;59: 1350-61.

11. Baber U, Mehran R, Sharma SK, Brar S, Yu J, Suh JW, Kim HS, Park SJ, Kastrati A, de Waha A, Krishnan P, Moreno P, Sweeny J, Kim MC, Suleman J, Pyo R, Wiley J, Kovacic J, Kini AS, Dangas GD. Impact of the everolimus-eluting stent on stent thrombosis: a meta-analysis of 13 randomized trials. J Am Coll Cardiol. 2011;58:1569-77.

\section{Online data supplement}

Online Appendix. Methods.

Online Table 1. Procedural characteristics.

Online Table 2. Clinical investigational sites.

Online Table 3. Study organisation.

Online Figure 1. Multivariate predictors of target vessel failure within one year of stent implantation. 


\section{Online data supplement}

\section{Online Appendix METHODS}

\section{PATIENT SELECTION, PROCEDURE, AND FOLLOW-UP}

The following procedural data were collected: lesion characteristics, total procedure time, antithrombotic and antiplatelet medications administered, and serious adverse events (SAEs), including serious bleeding according to GUSTO classification ${ }^{12}$. Patients with unsuccessful implant of a study device were followed only up to hospital discharge following the initial attempted index procedure. Enrolment at 14 centres was eventually capped at approximately 40 patients to prevent skewing the results with overrepresentation from high-volume centres.

\section{STUDY ENDPOINTS}

Secondary endpoints included stent thrombosis using Academic Research Consortium (ARC) definitions (i.e., definite or probable), major adverse cardiac events (i.e., cardiac death, MI, TVR), cardiac death, MI, TVR, all deaths, and non-cardiac deaths. Technical success was defined as successful deployment of the PROMUS Element stent to the target lesion without device malfunction.

\section{STATISTICAL METHODS}

Patient demographics, clinical history, risk factors, pre- and postprocedure lesion characteristics, procedure characteristics, and outcome variables were summarised using descriptive statistics for continuous variables (mean, standard deviation, number of observations, minimum, and maximum) and frequency tables for discrete variables. Kaplan-Meier plots of time-to-event variables were constructed with $95 \%$ confidence intervals. Cox models were performed to identify risk predictors with respect to TVF rates. Backward selection was used to identify significant predictors with the threshold to stay in the model set at 0.10 .

\section{RESULTS}

\section{LONGITUDINAL STENT DEFORMATION}

One case was attributed to a deep-seated guide catheter interacting with the proximal end of a deployed PROMUS Element stent, causing slight longitudinal compression, which was resolved with postdilation and additional stent deployment, without associated patient injury. In the second case, an LAD/diagonal branch bifurcation intervention, the guidewire was jailed by the proximal end of the stent, leading to subsequent unravelling of the guidewire into a filament proximal to the diagonal. During manoeuvres for successful retrieval of the wire with a snare, the proximal end of the implanted stent was minimally damaged. Post-dilation balloon inflations were performed along the entire stented segment and a stent was placed in the proximal LAD/left main. A small non-Q-wave MI (peak CK-MB $43 \mathrm{U} / \mathrm{L}$, troponin $2.4 \mathrm{ng} / \mathrm{mL}$ ) occurred post procedure and the patient was discharged two days later. Of these two patients with longitudinal stent deformation, only one experienced a small periprocedural enzyme leak. Neither patient has had any other clinical events reported up to the time this manuscript was published.

\section{Reference}

12. The GUSTO Investigators. An international randomised trial comparing four thrombolytic strategies for acute myocardial infarction. The GUSTO investigators. N Engl J Med. 1993;329:673-82.

\begin{tabular}{|c|c|c|c|c|}
\hline Overall predictors $(n=1,010)$ & Hazard ratio $\pm 95 \% \mathrm{Cl}$ & OR & $95 \% \mathrm{Cl}$ & $p$ value \\
\hline Thienopyridine $<6$ months & 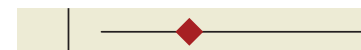 & 3.44 & $1.68,7.05$ & $<0.001$ \\
\hline Diabetes & 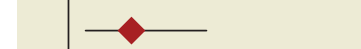 & 2.27 & $1.36,3.79$ & 0.002 \\
\hline Post-procedure dilatation & $\multimap$ & 2.02 & $1.17,3.47$ & 0.01 \\
\hline Prior $\mathrm{PCl}$ & - & 1.69 & $1.01,2.81$ & 0.04 \\
\hline Lesion type B2/C & - & 1.66 & $0.95,2.92$ & 0.08 \\
\hline & $\begin{array}{lllllll}0 & 1 & 2 & 3 & 4 & 5 & 6\end{array}$ & 7 & & \\
\hline Related to PE stent $(n=1,010)$ & Hazard ratio $\pm 95 \% \mathrm{Cl}$ & OR & $95 \% \mathrm{Cl}$ & $p$ value \\
\hline Vein graft & 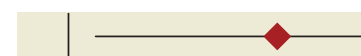 & 5.22 & $1.56,17.4$ & 0.007 \\
\hline Diabetes & $\rightarrow$ & 2.29 & $1.14,4.59$ & 0.02 \\
\hline Post-procedure dilatation & $\rightarrow$ & 2.04 & $1.00,4.18$ & 0.05 \\
\hline Prior PCl & - & 1.92 & $0.96,3.82$ & 0.06 \\
\hline & $\begin{array}{lllllll}0 & 1 & 2 & 3 & 4 & 5 & 6\end{array}$ & 7 & & \\
\hline
\end{tabular}

Online Figure 1. Multivariate predictors of target vessel failure within 1 year of stent implantation. 
Online Table 1. Procedural characteristics.

\begin{tabular}{|c|c|}
\hline Characteristics & 1,035 procedures \\
\hline Emergency procedure $(\%)^{*}$ & $20.2 \%(209 / 1,035)$ \\
\hline Pre-deployment IVUS used (\%) & $4.5 \%(60 / 1,321)$ \\
\hline Predilation (\%) & $63.4 \%(838 / 1,321)$ \\
\hline Stent deployment pressure (atm) & $15.1 \pm 2.90$ \\
\hline Post-dilation (\%) & $45.7 \%(604 / 1,321)$ \\
\hline $\begin{array}{l}\text { Post-procedure target lesion diameter } \\
\text { stenosis, \% }\end{array}$ & $1.7 \pm 5.94(1,321)$ \\
\hline Average stent diameter, $\mathrm{mm}$ & $2.9 \pm 0.46$ \\
\hline Stents implanted per lesion, $\mathrm{n}$ & $1.3 \pm 0.60(1,321)$ \\
\hline Average stent length per patient, mm & $34.0 \pm 23.66(1,010)$ \\
\hline Average stent length per lesion, $\mathrm{mm}$ & $26.0 \pm 16.56(1,321)$ \\
\hline Patients with multivessel stenting & $14.3 \%(144 / 1,010)$ \\
\hline Lesions with multiple stents & $20.7 \%(274 / 1,321)$ \\
\hline Lesions with overlapping stents & $14.5 \%(192 / 1,321)$ \\
\hline Bail-out stenting & $2.9 \%(29 / 1,010)^{\pi}$ \\
\hline \multicolumn{2}{|c|}{$\begin{array}{l}\text { Intent-to-treat analysis set. Values are mean } \pm \mathrm{SD}(\mathrm{N}) \text { or \% }(\mathrm{n} / \mathrm{N}) \text {. } \\
\text { *Includes staged procedures. "Includes study stents and non-study } \\
\text { stents. IVUS: intravascular ultrasound }\end{array}$} \\
\hline
\end{tabular}

Online Table 2. Clinical investigational sites.

\begin{tabular}{|c|c|c|}
\hline $\begin{array}{l}\text { Principal } \\
\text { investigator }\end{array}$ & Site name & Site location \\
\hline Rudolf Berger & Allgemeines Krankenhaus AKH & Vienna, Austria \\
\hline Steen Carstensen & Roskilde University Hospital & Roskilde, Denmark \\
\hline Peter Schwimmbeck & Klinikum Leverkusen & Leverkusen, Germany \\
\hline Josepa Mauri Ferré & H. Germans Trias i Pujol & Barcelona, Spain \\
\hline Paul Barragan & Polyclinique les Fleurs & Ollioules, France \\
\hline Edouard Benit & Virga Jesse Ziekenhuis & Hasselt, Belgium \\
\hline Jacques Berland & Clinique Saint-Hilaire Rouen & Rouen, France \\
\hline Ralf Birkemeyer & $\begin{array}{l}\text { Schwarzwald-Baar Klinikum } \\
\text { Villingen-Schwenningen }\end{array}$ & $\begin{array}{l}\text { Villingen-Schwenningen, } \\
\text { Germany }\end{array}$ \\
\hline Ezio Bramucci & IRCCS Policlinico S. Matteo & Pavia, Italy \\
\hline Carlo Briguori & Clinica Mediterranea & Naples, Italy \\
\hline Christophe Caussin & $\begin{array}{l}\text { Le Centre Chirurgical Marie } \\
\text { Lannelongue }\end{array}$ & Le Plessis Robinson, France \\
\hline Sarah Catherine Clarke & Papworth Hospital & Cambridge, United Kingdom \\
\hline Peter Anthony Crean & St. James's Hospital & Dublin, Ireland \\
\hline James Crowley & Galway University Hospital & Galway, Ireland \\
\hline Yunis Daralammouri & Zentralklinik Bad Berka (Rhoen) & Bad Berka, Germany \\
\hline A. Dirkali & Albert Schweitzer Ziekenhuis & Dordrecht, Netherlands \\
\hline Bernd Eber & Klinikum Kreuzschwestern & Wels, Austria \\
\hline Franco Fabbiocchi & Centro Cardiologico Monzino & Milan, Italy \\
\hline Jean Fajadet & Clinique Pasteur & Toulouse, France \\
\hline Dieter Fischer & $\begin{array}{l}\text { Medizinische Hochschule } \\
\text { Hannover }\end{array}$ & Hannover, Germany \\
\hline David Foley & Beaumont Hospital & Dublin, Ireland \\
\hline Bernard Karsenty & Clinique St. Martin & Pessac, France \\
\hline Tim Kinnaird & University Hospital of Wales & Cardiff, United Kingdom \\
\hline Guillaume Lecoq & CHP St. Martin & Caen, France \\
\hline Victor Legrand & $\begin{array}{l}\text { Centre Hospitalier } \\
\text { Universitaire Sart Tilman }\end{array}$ & Liege, Belgium \\
\hline Franz Leisch & AKH Linz & Linz, Austria \\
\hline Phil MacCarthy & King's College Hospital London & London, United Kingdom \\
\hline Bart Jan Meursing & Canisius Wilhelmina Ziekenhuis & Nijmegen, The Netherlands \\
\hline Raul Moreno & Hospital La Paz & Madrid, Spain \\
\hline Giuseppe Musumeci & Ospedali Riuniti di Bergamo & Bergamo, Italy \\
\hline Jawed Polad & Jeroen Bosch Ziekenhuis & $\begin{array}{l}\text { 's-Hertogenbosch, } \\
\text { Netherlands }\end{array}$ \\
\hline Gert Richardt & $\begin{array}{l}\text { Herzzentrum Segeberger } \\
\text { Kliniken GmbH }\end{array}$ & Bad Segeberg, Germany \\
\hline Declan Sugrue & $\begin{array}{l}\text { Mater Misericordiae University } \\
\text { Hospital }\end{array}$ & Dublin, Ireland \\
\hline Per Thayssen & University Hospital & Odense, Denmark \\
\hline Martyn Thomas & $\begin{array}{l}\text { Guy's and St. Thomas' NHS } \\
\text { Foundation Trust }\end{array}$ & London, United Kingdom \\
\hline Imre Ungi & $\begin{array}{l}\text { Dept. of Internal Medicine and } \\
\text { Cardiological Center }\end{array}$ & Szeged, Hungary \\
\hline Nikos Werner & Universitätsklinikum Bonn & Bonn, Germany \\
\hline Gerald Werner & Klinikum Darmstadt & Darmstadt, Germany \\
\hline Azfar G. Zaman & Freeman Hospital & $\begin{array}{l}\text { Newcastle-upon-Tyne, } \\
\text { United Kingdom }\end{array}$ \\
\hline Tobias Zeus & $\begin{array}{l}\text { Universitätsklinikum } \\
\text { Dusseldorf }\end{array}$ & Dusseldorf, Germany \\
\hline
\end{tabular}


Online Table 3. Study organisation.

\begin{tabular}{|l|l|}
\hline Principal investigator & $\begin{array}{l}\text { Martyn R. Thomas, MD } \\
\text { Guy's and St. Thomas' National Health Service Foundation Trust, London, United Kingdom }\end{array}$ \\
\hline Study sponsor & Boston Scientific Corporation, Inc., Marlborough, MA, USA \\
\hline Study conduct and data monitoring & PRA UK \\
& Raleigh, NC, USA \\
\cline { 2 - 3 } & Quintiles \\
& Bangalore, Karnataka, India \\
\hline Clinical events committee & Joseph Kannam, MD (Chair) \\
& Beth Israel Deaconess Medical Center \\
& Boston, MA, USA \\
\cline { 2 - 2 } & Germano Di Sciascio, MD \\
& Università Campus Bio-Medico \\
& Rome, Italy \\
\hline & Claude Hanet, MD \\
& UCL Mont-Godinne \\
& Brussels, Belgium \\
\hline & Goran Stankovic, MD \\
& Institute for Cardiovascular Diseases at the Clinical Center of Serbia \\
& Belgrade, Serbia \\
\hline
\end{tabular}

